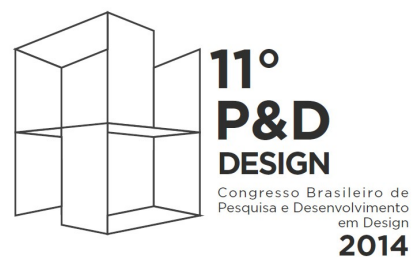

Gramado - RS

2014

De 29 de setembro a 2 de outubro de 2014

\title{
LEVANTAMENTO E IDENTIFICAÇÃO DOS ASPECTOS BÁSICOS PARA A CORRETA ESCOLHA DO TRAVESSEIRO DE FIBRA
}

\author{
Locks, Rafael Teixeira \\ Universidade Federal de Santa Catarina, \\ locks.rafael@gmail.com.br \\ Merino, Giselle Schmidt Alves Díaz \\ Universidade Federal de Santa Catarina, \\ gisellemerino@gmail.com.br \\ Merino, Eugenio Andrés Díaz \\ Universidade Federal de Santa Catarina, \\ Eugenio.merino@ufsc.brl
}

\begin{abstract}
Resumo: Durante uma noite de sono existem interações entre o ser humano e os diversos objetos que o envolvem: o colchão, o cobertor, o travesseiro, a iluminação, entre outros. Entender como acontece a interação do usuário, elemento central deste sistema, com as demais partes pode melhorar significativamente a qualidade do sono da população. Este estudo tem como objetivo levantar e identificar aspectos básicos para a correta escolha do travesseiro de fibra. Como resultado preliminar do estudo identificaram-se três aspectos a serem avaliados no momento da seleção do travesseiro: (1) a relação existente entre a seleção correta do travesseiro de fibra e as diferentes posições de dormir; (2) a pré-disposição do usuário a problemas respiratórios; (3) a avaliação da condição de uso do colchão. Destaca-se, como contribuição da pesquisa, este novo olhar para 0 ato de dormir que integra conhecimentos específicos da ergonomia com a qualidade de vida do usuário.
\end{abstract}

Palavras-chave: Ergonomia, Qualidade do sono, Travesseiro.

\begin{abstract}
Sleep night can be considered a big ergonomic system, where there are interactions between humans and the various objects that surround it: the mattress, a blanket, a pillow, lighting and more. Understanding how the user interaction happens, who is the central element of this system, with other parts can improve people quality sleep. This study search to identify and raise issues related to ergonomics sleep,
\end{abstract}




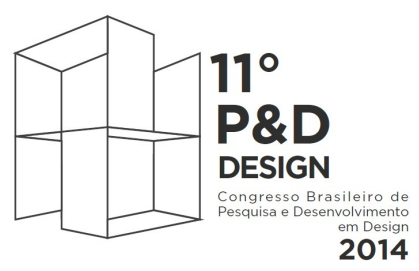

Gramado - RS

2014

De 29 de setembro a 2 de outubro de 2014

using the pillow as a focus. As a result of the study identified three aspects to be evaluated at the time of pillow selection: (1) the relationship between the fiber pillow correct selection and different sleeping positions, since the pillow serves to align the head to the spine during sleep; (2) user probability to respiratory problems; (03) evaluation of mattress use conditions. Another issue identified was the absence of a regulatory standard for the design and specification of the pillow product in the country, raising questions about the topic during the selection process.

Key-word: Ergonomics,quality sleep, pillow.

\section{INTRODUÇÃO}

Segundo Bonfim, (2010), estudos desenvolvidos para a Universidade de Chicago, com pessoas entre 18 e 27 anos que tiveram seu sono reduzido em quatro horas durante seis dias, afirmam que uma pessoa deve dormir em média oito horas por dia. Ao final do período de abstinência do sono, o grupo em estudo apresentou níveis de insulina semelhantes aos dos portadores de diabetes e o funcionamento dos seus organismos era semelhante ao de uma pessoa de 60 anos. Este período, oito horas de sono, quando utilizado de forma correta, segundo Bonfim (2010), traz benefícios como: melhor desempenho físico e mental, fortalecimento do sistema imunológico e maior longevidade, além do relaxamento e descanso da musculatura. Sobre o contexto da qualidade de vida, muito se tem discutido sobre a importância de um sono reparador e suas consequências nas atividades diárias dos usuários. Entretanto, pouco está sendo abordado sobre a influência do produto travesseiro de fibra como parte para a obtenção de um sono de qualidade.

O objeto de estudo selecionado para esta pesquisa foi o travesseiro de fibra, composto por uma capa retangular de tecido $100 \%$ algodão e o enchimento de fibra de poliéster. Suas características de conforto, maleabilidade e ampla utilização fundamentam sua escolha. O mesmo tem como finalidade suportar o peso da cabeça, mantendo-a alinhada com a coluna e garantindo o relaxamento da musculatura do pescoço. Como problemática foi percebida a falta de informação em como escolher o travesseiro de fibra ideal. Levantar e identificar os aspectos básicos relacionados ao produto travesseiro de fibra se torna o objetivo desta pesquisa, com a finalidade de auxiliar o usuário na escolha do mesmo. Segundo Nascimento e Morais (2010), a qualidade de sono pode ser influenciada por fatores psicológicos, condições do local em que se dorme e o estilo de vida do usuário. A escolha incorreta do travesseiro de fibra pode 


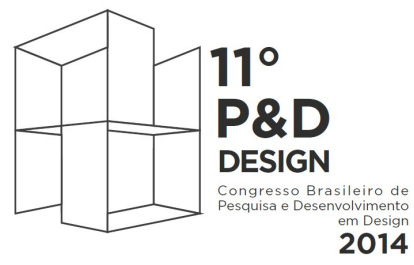

Gramado - RS

2014

De 29 de setembro a 2 de outubro de 2014

gerar uma diminuição da qualidade do sono e por esse motivo esta pesquisa se justifica, uma vez que já existem no mercado soluções apropriadas para cada usuário. A falta de conhecimento da população, juntamente com a pouca habilidade dos fabricantes em deixar clara essa recomendação nas embalagens, pode tornar o processo de compra do produto complexo e algumas vezes ineficiente.

\section{DESENVOLVIMENTO}

\subsection{Procedimentos metodológicos}

Segundo Silva e Menezes (2005), a pesquisa de natureza básica e bibliográfica propõe gerar conhecimento novo e de interesse universal. Sua abordagem qualitativa descritiva busca trazer ao objeto de pesquisa uma relação dinâmica com o mundo atual. O processo de seleção do travesseiro de fibra é considerado uma atividade do cotidiano das pessoas, por esse motivo se faz fundamental abordá-lo de forma sistêmica, definido os aspectos corretos a serem verificados para a seleção do mesmo. Entender que a correta seleção do travesseiro de fibra não depende, exclusivamente, do toque do mesmo, gera a necessidade de investigação dos demais aspectos relevantes para a correta seleção do travesseiro de fibra e que podem influenciar na qualidade do sono.

Em conformidade com o objetivo da pesquisa, a execução desta obedecerá às seguintes fases: FASE 1 - Identificação e conceituação do problema. FASE 2 Determinação do objetivo da pesquisa, utilizando como recorte o estudo da categoria de travesseiros de fibra. FASE 3 - Levantamento bibliográfico, utilizando como base de dados da pesquisa: artigos / dissertações e livros com abordagem em sistemas ergonômicos. FASE 4 - Representação do objeto de pesquisa, travesseiro de fibra, quanto à sua história, finalidade, utilização e benefícios. FASE FINAL - Divulgação dos resultados preliminares na forma de orientação para o consumidor / usuário em como selecionar o travesseiro de fibra ideal.

\subsection{Estudo da ergonomia aplicada}

No estudo do produto travesseiro percebe-se a necessidade de uma abordagem interdisciplinar, relacionando conhecimentos do design, fisiologia, medicina e engenharia. Até a presente data, não existe uma norma na Associação Brasileira de Normas Técnicas que explique a correta forma de especificação e utilização do travesseiro. Tal fato aumenta, exponencialmente, a baixa qualidade de informações sobre o assunto. Entendendo que a ergonomia é uma disciplina científica e orientada para uma abordagem sistêmica de todos os aspectos da atividade humana, se faz 


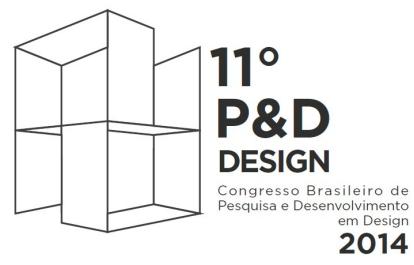

Gramado - RS

De 29 de setembro a 2 de outubro de 2014

necessário um olhar crítico e contemporâneo sobre as relações existentes entre o usuário e os objetos que o cercam durante a noite de sono. A forma como se dormia há um século era bem diferente de como se dorme hoje. Isso fez com que o estudo ergonômico nesta área evoluísse à medida que os produtos que compõem este sistema se modificaram. Segundo Anselmo (2013), a ergonomia do repouso ou do sono trata da adaptação e adequação do ambiente ao repouso, facilitando a relação entre os acessórios do quarto, como o colchão e outros, às particularidades de cada usuário. Travesseiros, almofadas, lençóis e a iluminação do quarto devem ser dimensionados ou redimensionados de acordo com um estudo da postura do usuário enquanto dorme. Segundo Verhaert (2011), ergonomic in bed é o domínio das pesquisas sobre o estudo do sono e da ergonomia. Para o mesmo, a questão-chave de um sistema do sono perfeito, em estado de arte, está em como aperfeiçoar o projeto do colchão favorecendo a qualidade do sono dos seres humanos.

A representação gráfica abaixo demonstra o usuário como elemento central nas interfaces durante o sono, e conectados ao usuário existem quatro elementos distintos que podem ser classificados em dois grupos diferentes.

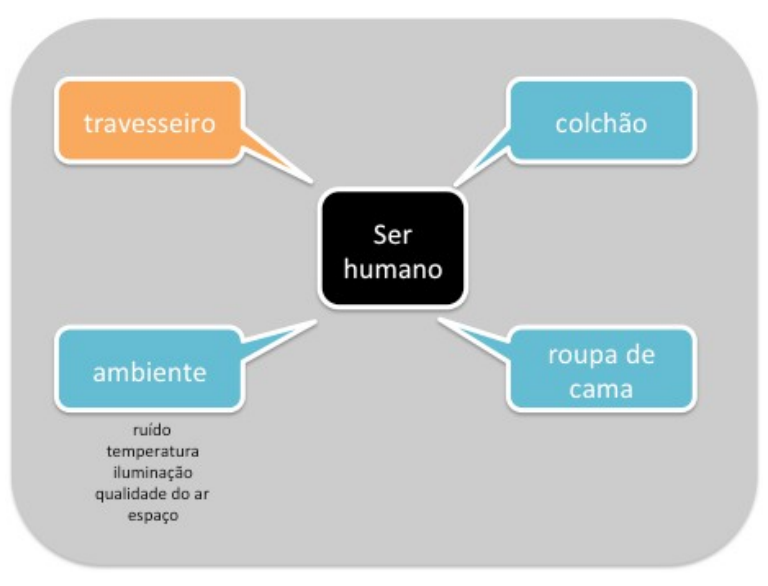

Figura 1 - Representação gráfica, relações ser humano $X$ interfaces durante o sono. Fonte - Elaborada pelo autor, com base na pesquisa realizada.

O primeiro grupo é representado pelo elemento ambiente, o qual é composto por: ruído, temperatura, iluminação, qualidade do ar, espaço, etc. Estes são fundamentais para a obtenção do sono de qualidade. Entretanto, as caracterísitcas individuais do usuário não intereferem diretamente nos elementos. Pode-se dizer que estes elementos nas mesmas condições de regulagem atendem a maioria das pessoas e portanto podem ser considerados genéricos. Como exemplo, pode ser citada a iluminação, que, durante a preparação e o ato do sono, deve estar de 17 a $20{ }^{\circ} \mathrm{C}$, e essa condição de temperatura satisfaz a maioria das pessoas. Tal raciocínio pode ser aplicado à iluminação, ruído, espaço e qualidade do ar, uma vez que, para existir a 


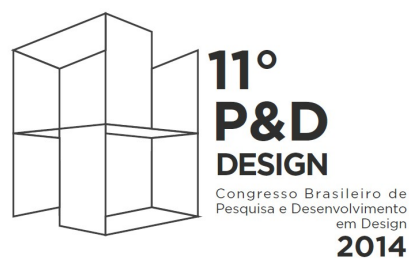

Gramado - RS

De 29 de setembro a 2 de outubro de 2014

obtenção de um sono de qualidade, se fazem necessários: luminosidade reduzida, não existência de ruídos e uma boa qualidade do ar.

O segundo grupo é representado pelos elementos: travesseiro, colchão e roupa de cama, e sua seleção depende diretamente das características antropométricas de cada usuário. Características como altura, peso, sexo e posições de dormir interferem diretamente na seleção dos mesmos. Então, considerar uma única regra para a sua seleção torna-se um equívoco. Cada elemento da representação gráfica possui uma função específica na qualidade do sono do usuário. A iluminação, temperatura, ruído e qualidade do ar são elementos que não têm contato direto físico com o usuário e possuem como função proporcionar condições para a efetivação do sono com maior rapidez e qualidade. No segundo grupo, onde os objetos têm contato direto com o usuário, cada elemento possui sua função específica: o colchão tem como função garantir o suporte do corpo e proporcionar o conforto tátil durante o sono; a roupa de cama traz o conforto térmico e tátil durante o sono; e, por fim, e objeto desta pesquisa, o travesseiro tem como principal função criar o alinhamento entre a cabeça e a coluna atráves do suporte da cabeça.

\subsection{Qualidade do sono}

Segundo Silva et al. (1994), o sono tem sido definido como um estado fisiológico complexo altamente regulado e controlado, em que ocorrem alterações dos processos fisiológicos e comportamentais, com mobilidade relativa e aumento do limiar de respostas aos estímulos. O sono era considerado uma experiência passiva até que os estudos nos anos de 1950 revelaram a existência de dois padrões fundamentais de sono: com movimentos oculares rápidos (REM) e sem movimentos oculares rápidos (NREM), sendo este último ainda composto por quatro etapas em grau crescente de profundidade - estágios I, II, III e IV.

O sono NREM compreende o sono profundo, durante o qual é mais difícil ser despertado. É considerado como a fase restauradora do sono, necessária para a sensação de descanso e renovação de energia mental para as atividades diárias. Já no sono REM os olhos movem-se rapidamente em várias direções, mesmo permanecendo fechados, a respiração torna-se mais ofegante, irregular e superficial, e a frequência cardíaca e pressão arterial se elevam. Durante esse tipo de sono, a musculatura dos braços e pernas fica temporariamente paralisada. É nesta fase do sono que existe o estímulo das regiões do cérebro responsáveis pelo aprendizado e consolidação da memória. Um ciclo noturno previsível de 90 a 110 minutos, conhecido como ciclo vigília sono, marca a variação entre os quatro estágios do sono NÃO REM para o sono REM. Um adulto passa por quatro a cinco ciclos completos de sono em um período de 8 horas. Cada pessoa tem ciclos de sono totalmente individuais, e cada ciclo, por sua 


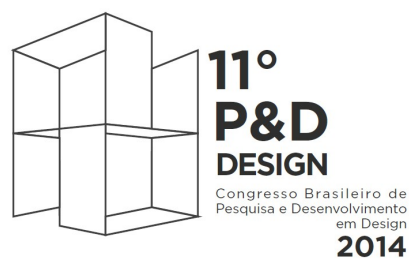

Gramado - RS

De 29 de setembro a 2 de outubro de 2014

vez, difere dos outros inconfundivelmente. Normalmente, no primeiro terço da noite a fase NÃO REM dura mais tempo que a fase REM, no decorrer da noite a fase NÃO REM se torna menor até desaparecer, permanecendo somente a fase REM.

Pensando que o processo de globalização trouxe grandes mudanças na vida das pessoas, onde as jornadas de trabalho estão cada vez mais contínuas e em condições distantes das ideais. Se preocupar com os fatores que possam interferir na qualidade do sono se torna fundamental. Nesta pesquisa, o ato de dormir está sendo considerado um sistema, devido às interações evidenciadas. Todos os fatores, que interagem com o usuário durante o sono contribuem, quando selecionados e dimensionados corretamente, na qualidade do sono do mesmo. Dormir bem traz benefícios tanto para as atividades físicas quanto cognitivas. O reflexo deste novo estilo de vida contemporâneo, principalmente em grandes centros urbanos, vem se percebendo nas últimas décadas através de uma diminuição da qualidade do sono. Segundo pesquisa desenvolvida pelo Laboratório Roche e coordenada pela Sociedade Brasileira de Neurofisiologia (2004), foram ouvidas 22.518 pessoas em 11 cidades diferentes do país, traçando um perfil detalhado do insone brasileiro. Os dados comprovam que a população possui dificuldades para dormir. Cerca de $45 \%$ da população classificaram seu sono como ruim ou regular. Outros $32 \%$ relataram dificuldade para começar a dormir e $25 \%$ disseram acordar com frequência e não conseguir pregar mais os olhos. A recomendação para buscar a melhora da qualidade do sono é adquirir hábitos de higiene do sono e preparar-se psicologicamente para o mesmo. Algumas atitudes simples - como: preparar o quarto para o ato de dormir, mantendo-o silencioso, escuro e com temperatura entre 17 e $20^{\circ} \mathrm{C}$; deitar e levantar todos os dias nos mesmos horários; certificar-se de que o colchão e travesseiros estão selecionados de acordo com as características do usuário; e evitar a ingestão de bebidas alcoólicas e comidas gordurosas antes de dormir - podem ajudar na qualidade do sono.

\subsection{Travesseiro}

Um travesseiro é uma espécie de almofada feita usualmente de fibra, pena, algodão, espuma, entre outros materiais, que se utiliza na cabeceira da cama, servindo para descansar a cabeça enquanto se dorme. 0 mesmo tem como finalidade suportar o peso da cabeça, mantendo-a alinhada com a coluna e garantindo o relaxamento da musculatura do pescoço. Em média o peso da cabeça de uma pessoa representa dez por cento do peso da mesma, então, o travesseiro deverá ter a capacidade de manter este peso quando apoiado e esta característica do travesseiro é chamada de suporte. Ao dormirmos com a coluna, tronco e cabeça alinhados, ajudamos o organismo a executar a livre circulação sanguínea e dos estímulos elétricos enviados pelo cérebro 


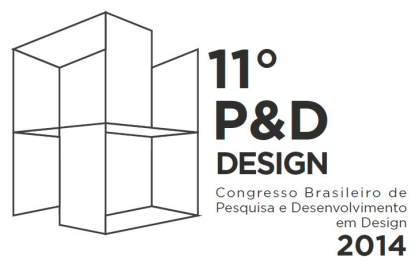

Gramado - RS

2014

De 29 de setembro a 2 de outubro de 2014

aos órgãos do nosso corpo. A seguir, a Figura 2 - Representação gráfica do correto alinhamento entre a cabeça e a coluna durante o sono.

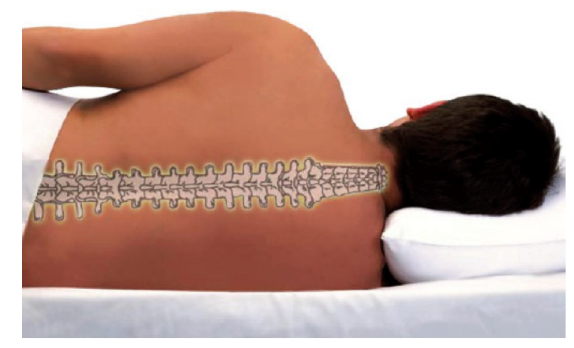

Figura 2 - Representação gráfica do correto alinhamento entre a cabeça e a coluna durante o sono. Fonte - Campachi, Mazoni (2012, p.25)

Uma característica do travesseiro é ser considerado um produto doméstico utilizado por todas as classes sociais, e isso reforça seu carater de produto inclusivo. Não foi identificado ao certo de quando data este hábito de usabilidade, uso do travesseiro, e o homem é o único que o tem. E, ao contrário de outras invenções e descobertas próximas, como da cama ou do colchão, não se conhece nenhum relato sobre seu inventor. Segundo LIMA (2002), existem alguns poucos relatos históricos relacionados a este artefato. Estudar a história do travesseiro é perceber que ele faz parte da história da humanidade, desde seus primórdios. Relatos bíblicos já demonstraram sua utilização. As tumbas no início da Era Cristã eram escavadas em espécies de cavernas e no local onde repousariam os corpos sempre deixavam, no lado que seria para a cabeça, uma parte mais alta para a sua elevação. Segundo Campachi e Mazoni (2012), no Egito antigo o travesseiro era um produto encontrado nos sarcófagos dos faraós e tinha a conotação de status. Nos países asiáticos, como China e Japão, utilizam-se ainda hoje pequenos pedaços de bambu ou madeira para o apoio da nuca ao deitar-se. Acredita-se que, desde que o homem existe, ele utiliza instintivamente artifícios para repousar a cabeça com a intenção de proporcionar condições adequadas e confortáveis para dormir.

Com o passar dos anos e o desenvolvimento das diferentes tecnologias relacionadas ao sono, foram desenvolvidos diversos tipos de travesseiro com materiais e propriedades específicas. Atualmente existem várias opções de enchimento, tecidos e formatos no mercado. Cada tecnologia tem suas particularidades. $\mathrm{O}$ travesseiro feito com a espuma de poliuretano tem como característica não ceder facilmente ao peso da cabeça do usuário, o que não proporciona uma sensação de conforto plena. A segunda tecnologia, travesseiro de fibra, tem como característica oferecer suporte e conforto ao usuário, além de ser lavável e bastante maleável. O travesseiro feito de 


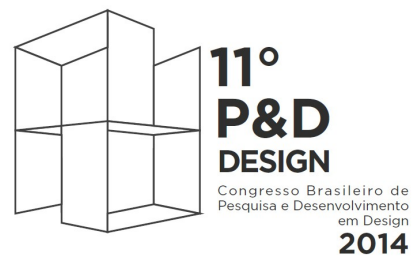

Gramado - RS

De 29 de setembro a 2 de outubro de 2014

espuma viscoelástica, conhecido comercialmente como travesseiro NASA, possui característica ventilável que permite uma higiene do travesseiro mais eficiente. $O$ mesmo é bastante confortável, e tem como característica negativa não poder ser lavado. O travesseiro de fibra, objeto desta pesquisa, possui como componentes a capa e o enchimento. A capa é geralmente de tecido, podendo ter em sua composição algodão ou poliéster e sua função é delimitar a área de preenchimento da fibra e proporcionar o formato ao travesseiro. O segundo componente do travesseiro de fibra é o enchimento, este tem a função de trazer a característica de suporte ao mesmo, além conferir maior ou menor percepção de conforto ao usuário. Sua composição é geralmente de fibra de poliéster ou algodão. Conforto, maleabilidade e ampla utilização fundamentaram sua escolha nesta pesquisa.

$\mathrm{O}$ ato de dormir afeta diretamente o sistema músculo-esquelético, podendo atingir negativamente a coluna vertebral quando não existir o correto alinhamento entre as partes: cabeça e coluna. Por tal motivo se tem investigado as diferentes posições de dormir, visto que esta pode ser uma fonte de geração de problemas de coluna durante o período de sono. O posicionamento errado durante o sono pode acarretar o stress e o esmagamento da coluna vertebral, podendo proporcionar patologias como: dor lombar, lordose e escoliose. Não foi comprovada pela ciência a forma ideal para dormir. Segundo Haex (2004), o melhor posicionamento na hora de dormir é o que reduz o stress acumulado e promove o relaxamento dos músculos, proporcionando assim um condicionamento equilibrado do corpo.

\subsection{Posições de dormir}

Existem três diferentes tipos de posições de dormir: posição de decúbito dorsal ou de lado, posição de bruços ou de barriga para cima. Segundo Verhaert (2011), em geral as características mecânicas do sistema do sono deveriam depender de dois aspectos antropométricos: o contorno do corpo do usuário e a distribuição do peso do mesmo. Estudo da Universidade Leuven - Bélgica, com o objetivo de entender como a espinha humana suporta os efeitos do sono em 17 pessoas normais, identificou uma relação entre o colchão e a qualidade do sono, em que ambos são afetados diretamente pelas características antropométricas individuais e pela postura durante o sono.

Tal afirmação, resultado do estudo das relações do usuário com o colchão, também pode ser aplicada ao uso do produto travesseiro, pois ambos se complementam para proporcionar o perfeito alinhamento entre a coluna, cabeça e o quadril. Abaixo, a Figura 3, representando a relação existente entre as características antropométricas do usuário, no caso: contorno do corpo, distribuição do peso e o produto travesseiro. 


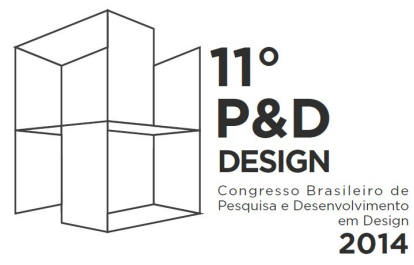

Gramado - RS

2014

De 29 de setembro a 2 de outubro de 2014

O elo que as conecta é a forma como o usuário dorme, chamada de posições de dormir.

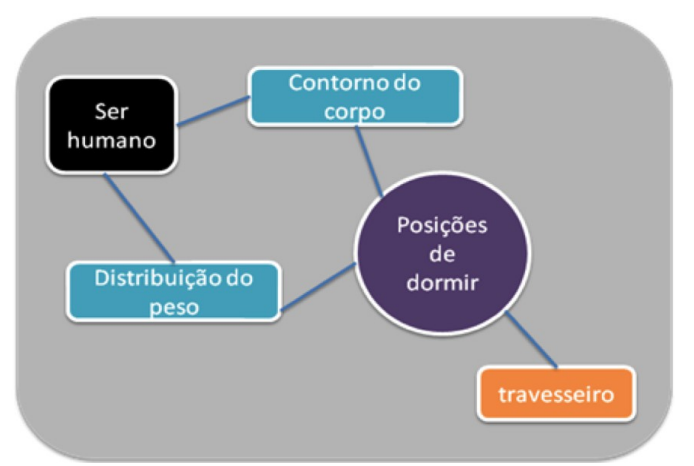

Figura 3 - Relação entre posições de dormir $X$ aspectos antropométricos do usuário Fonte - Elaborada pelo autor, com base na pesquisa realizada.

Assim, as posições de dormir tornam-se o elemento central no processo de seleção do correto travesseiro de fibra. A primeira, posição de lado, é a mais indicada pelos especialistas, pois permite um maior conforto e eficiência. Para tal é necessária a utilização de dois travesseiros, um dando suporte para a cabeça e outro, entre os joelhos. Para as pessoas que dormem nessa posição recomenda-se um travesseiro mais alto e com suporte extrafirme. Essa necessidade é gerada pelo maior espaço formado entre a altura do ombro e a cabeça, considerando que ambos precisam estar alinhados. Um segundo travesseiro é recomendado entre os joelhos com o objetivo de manter o alinhamento entre o quadril e a coluna. A segunda posição de dormir, posição de dormir de costas, também é recomendada pela maioria dos especialistas, pois permite o perfeito alinhamento da coluna com a utilização de travesseiros. Para este caso é recomendada a utilização de um travesseiro com suporte e altura média, para sustentar a cabeça. Outro travesseiro é indicado abaixo dos joelhos para alinhar o quadril aos joelhos. A terceira posição de dormir é a de bruços; esta não é indicada pela maioria dos especialistas, pois causa torção no pescoço e origina desconforto na região da cervical e da lombar. Alguns fabricantes, entendendo que existe um mercado que dorme nessa posição, desenvolveram travesseiros com suporte médio e altura muito baixa. Estes são indicados para as pessoas que dormem na posição de bruços, pois permitem melhor alinhamento entre a cabeça e a coluna.

\subsection{A influência do colchão na escolha do travesseiro}

O colchão é um componente do sistema do sono, possui função similar ao do travesseiro, entretanto deve dar sustentação ao corpo. Uma boa seleção do travesseiro não teria êxito, caso o colchão não estivesse adequado ao usuário. Por esse motivo, o mesmo faz parte do contexto de seleção do travesseiro. $O$ colchão ideal não 


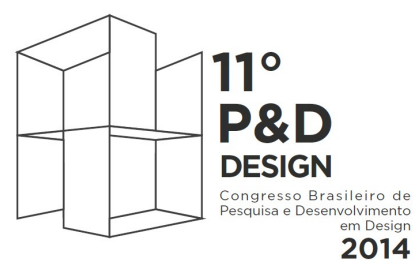

Gramado - RS

2014

De 29 de setembro a 2 de outubro de 2014

pode trazer a sensação de ser mole ou duro quando o usuário estiver deitado, pois em ambos os casos ele proporcionará desconforto e dores devido ao não alinhamento entre a cabeça, a coluna e o quadril. O colchão ideal deve se ajustar ao corpo do usuário proporcionando conforto e suporte igual em todas as partes do mesmo. Não existe, como no travesseiro, uma variação de altura e/ou tipo de colchão em relação à posição de dormir.

\subsection{Sensibilidade do usuário a alergias}

Segundo Lança (2010), a alergia é uma situação na qual o organismo apresenta uma resposta imunológica de defesa diferente da resposta protetora esperada. O termo "alergia" vem do grego allos, que significa alteração do estado original. Os seus tipos mais comuns estão relacionadas à intolerância ao pólen, partículas de pó, esporos de fungos, alimentos, etc. Quando a alergia afeta o sistema respiratório é chamada de alergia respiratória. Segundo dados da Associação Brasileira de Alergia e Imunopatologia (Asbai), cerca de $30 \%$ da população brasileira possuem algum tipo de alergia, e $20 \%$ são crianças. Segundo Lança (2010), as doenças alérgicas têm origem multifatorial e complexa. Acredita que, para sua ocorrência, tem que haver uma combinação entre a pré-disposição genética do ser humano e uma situação no ambiente facilitadora.

Nesse sentido, se faz necessário avaliar o travesseiro de fibra sob esse aspecto. Segundo Galvão (2013), em dois anos de uso um terço do peso do travesseiro é formado por ácaros. Durante a noite existe um processo natural de esfoliamento da pele, e esse resíduo, quando depositado no travesseiro, cria condições para o aparecimento e multiplicação dos ácaros no produto. Assim, o travesseiro antigo ou que não tenha sido higienizado pode ser uma fonte de doenças respiratórias. Para pessoas que possuem maior sensibilidade ao aparecimento destas doenças, recomenda-se a utilização de um travesseiro antiácaros. Existem no mercado travesseiros desenvolvidos com nanotecnologia, íons de prata, que possuem a capacidade de não deixar ocorrer o aparecimento e a multiplicação dos ácaros.

\subsection{Resultados preliminares}

Com a evolução das tecnologias e o novo estilo de vida do homem contemporâneo, se faz necessário potencializar a qualidade do sono. Dessa forma, se torna relevante o estudo das interfaces entre o usuário e os objetos que o cercam durante o sono. Entender como este sistema se relaciona ajudará na evolução do tratamento de patologias do sono e aumentará a qualidade de vida da população.

O travesseiro de fibra é um objeto utilizado no cotidiano por uma grande quantidade de pessoas, mas este produto de toque macio pode, quando mal utilizado, interferir 


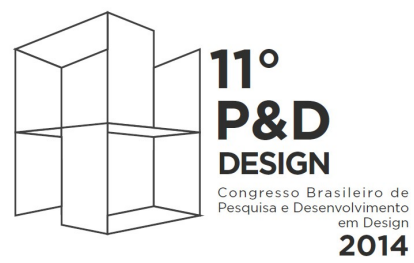

Gramado - RS

De 29 de setembro a 2 de outubro de 2014

negativamente na qualidade do sono do usuário. Entendendo que o objetivo do mesmo é criar o perfeito alinhamento entre a cabeça e a coluna e que as posições de dormir interferem diretamente nesse alinhamento, se faz necessário separar essa análise nas três diferentes posições de dormir. O processo de seleção do travesseiro de fibra será mais assertivo a partir do momento em que usuário tiver a consciência da sua posição de dormir e não somente escolher o travesseiro de forma instintiva, por meio da sensação de conforto ao toque. Com o objetivo de ajudá-lo a identificar o correto travesseiro de fibra, foi desenvolvido o diagrama abaixo, representado na Figura 4, com os aspectos a serem avaliados para correta seleção do travesseiro de fibra.

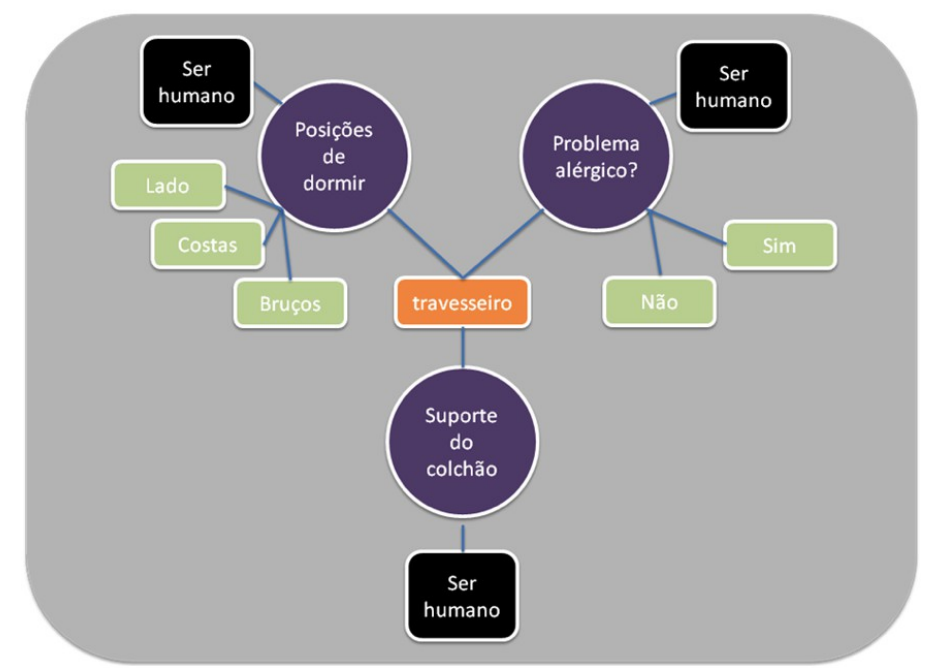

Figura 4 - Representação gráfica, aspectos a serem avaliados para correta seleção do travesseiro de fibra.

Fonte - Elaborada pelo autor, com base na pesquisa realizada.

O primeiro passo que deve ser avaliado pelo usuário é a posição em que o mesmo dorme. Esse aspecto é fundamental, pois nele estão contidas duas informações antropométricas do usuário: contorno do corpo, no caso ombro/pescoço e cabeça, e a distribuição do peso da cabeça sobre o travesseiro. Para pessoas que dormem de lado, é indicado o travesseiro de fibra de suporte extrafirme; este é mais alto e possui o toque mais denso, por ter uma maior quantidade de massa. Seu objetivo será preencher a área existente entre a cabeça e o ombro enquanto estiver deitado. Para os que dormem de barriga para cima é indicado escolher o travesseiro de fibra de suporte firme, ele terá uma altura média e um toque mais macio quando comparado com o travesseiro extrafirme. Já, para quem dorme de bruços, o travesseiro recomendado é o de suporte médio, pois possui a altura mais baixa de todos e o toque mais macio. O segundo aspecto que deve ser avaliado na seleção do travesseiro de fibra é a pré-disposição do usuário a problemas respiratórios. Durante o uso contínuo 


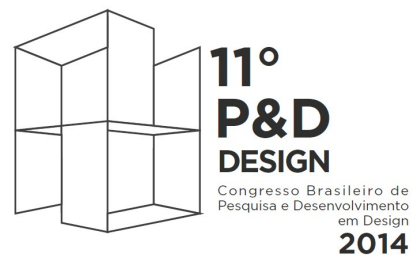

Gramado - RS

De 29 de setembro a 2 de outubro de 2014

do travesseiro pode haver o aparecimento e multiplicação de ácaros e, para pessoas com alergias, o ideal é a seleção de um travesseiro com tecnologia íons de prata, que não permite a proliferação dos mesmos. Por fim, se faz necessária a verificação do usuário em relação ao colchão em uso. Caso este não esteja em boas condições, permitindo o perfeito ajuste do corpo, o mesmo poderá interferir na eficiência do travesseiro selecionado em uso.

Outro ponto encontrado que dificulta a correta especificação deste produto reside na ausência de uma norma regulamentadora para o dimensionamento e especificação do produto no país. Portanto, organizar este pensamento leva a perceber a necessidade do desenvolvimento de um sistema fundamentado em pesquisas antropométricas, além da investigação de outros fatores que possam interferir diretamente na seleção correta do travesseiro de fibra.

\section{CONCLUSÃO}

Esta abordagem de avaliação de uma noite de sono como um sistema onde existem diversas interfaces é relativamente nova, por esse motivo, tal pesquisa se destaca pelo pouco material publicado. Entender que a qualidade de vida do usuário está diretamente relacionada com a sua qualidade do sono amplia a necessidade de aprofundamento da pesquisa, tanto na interface existente do mesmo com o travesseiro, quanto em suas demais interfaces do sistema.

Os resultados preliminares da pesquisa já demonstraram que a identificação dos aspectos básicos para escolha do travesseiro pode contribuir significativamente para ajudar o usuário no processo de seleção do mesmo e, consequentemente, no aumento da qualidade do seu sono. Entretanto, a pesquisa se encontra em desenvolvimento e buscará, nesta nova fase, um maior detalhamento das características antropométricas do usuário com o produto travesseiro.

Destaca-se, como contribuição da pesquisa, este novo olhar para o ato de dormir que integra conhecimentos específicos da ergonomia com a qualidade de vida do usuário. Ela poderá contribuir com conhecimento capaz de retroalimentar de informações outros processos, como o projeto de produtos específicos para este ato e o desenvolvimento de um manual para orientação ao usuário.

\section{REFERÊNCIAS}

Associação Brasileira de Normas Técnicas. NBR 6021: Apresentação de periódicos. Rio de Janeiro, 1994. 


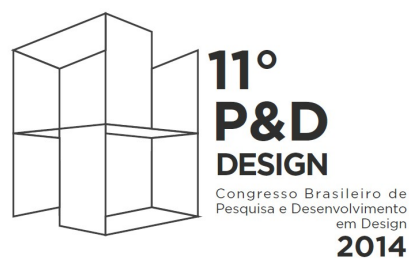

Gramado - RS

De 29 de setembro a 2 de outubro de 2014

ANSELMO, Marcelo. A ergonomia do repouso: considerações sobre uma boa postura de sono. Fórum integrador do bem estar. Disponível na internet por http em:

$<$ http://fibemestar.com.br/sono/a-ergonomia-do-repouso-consideracoes-sobre-umaboa-postura-de-sono>. Acesso em 25 set. 2013.

BONFIM, Marco Aurélio Gouvêa. A importância do sono e as principais interferências. ABC da Saúde.Disponível na internet por http em:<http://www.abcdasaude.com.br/artigo.php?3047>. Acesso em 29 set. 2013. CAMPACHI, Rafael, MANZONI, Milene Franciele de.TravesseiroEcológico. 2012. Tese (Graduação) -Faculdade de Tecnologia e Ciências de Barigui, Curso de Desenho Industrial.

GALVÃO, Clóvis.Saiba como evitar ácaros e evitar reações alérgicas dentro de casa. Revista bem estar. Disponível na internet por http em: <http://g1.globo.com/bemestar/noticia/2013/05/saiba-como-eliminar-acaros-e-evitarreacoes-alergicas-dentro-de-casa.html $>$.Acesso em 16 nov. 2013.

HAEX, Bart.Back and bed: ergonomic aspects of sleeping. Londres: CRC Press. 2005. IEA. InternationalErgonomiesAssociation. São Paulo: Pontes. 2000.

LIMA, Márcia de Barbosa, VIDAL, Márcio Cesar Rodriguez, Uma reflexão sobre o critério de concepção e adequação do produto travesseiro para apoio de cabeça. In: VII Congresso Latino Americano de Ergonomia. Recife, 2002.

LANÇA, Márcio Ataíde.Alergia respiratória (rinite). ABC da Saúde. Disponível na internet por http em: <http://www.abcdasaude.com.br/artigo.php?18>. Acesso em 16 nov. 2013.

MORAES, Thayse Vilela de, NASCIMENTO, Leonardo Lopes do.Análise da qualidade do sono e da qualidade de vida nos técnicos de enfermagem de Jataí. Revista eletrônica Saúde e Ciência. Disponível na internet por http em:<http://www.rescceafi.com.br/vol1/3-13.pdf>. Acesso em 15 nov. 2013.

Portal Altenburg Indústria Têxtil. Catálogos de produtos.Disponível na internet por http em:<www.altenburg.com.br>. Acesso em: 03 de out. 2013.

Portal Associação Brasileira de Alergia e Imunopatologia. Revista ASBAI. Disponível na internet por http em:<www.sbai.org.br>. Acesso em 15 de nov.2013.

SILVA, EdnaLúcia da, MENEZES, EsteraMuszkat.Metodologia da Pesquisa e Elaboração de Dissertação. Florianópolis: UFSC. 2005.

SILVA, Lídia Ester Lopes da et al. Fatores que interferem na qualidade do sono de pacientes internados.Revista eletrônica de enfermagem.Disponível na internet por http em:<http://www.revistas.ufg.br/index.php/fen/search/results $>$. Acesso em 10 set. 2013.

VERHAERT, Vicent et al, Ergonomics in bed design: the effect of spinal alignment on sleep parameters. In: Ergonomics. Bélgica, 2011. 